\title{
Modelling In-situ Factors Affecting Bud's Growth of Rafflesia kerrii Meijer in Lojing Highlands, Kelantan, Peninsular Malaysia
}

\author{
Abdul Hamid Mar Iman', Nor Hizami Hassin², Muhamad Azahar Abas² and \\ Zulhazman Hamzah ${ }^{2}$ \\ ${ }^{1}$ Faculty of Veterinary, Universiti Malaysia Kelantan, Pengkalan Chepa, 16100 Kota Bharu, Kelantan, Malaysia \\ ${ }^{2}$ Faculty of Earth Science, Universiti Malaysia Kelantan, 17600 Jeli, Kelantan, Malaysia
}

\begin{abstract}
Studies on the statistical approach to analyzing growth factors of bud's growth in the genus Rafflesia have been lacking. This study quantified the effects of eight selected ecological factors hypothesized to be influencing bud's growth (diameter and circumference) of Rafflesia kerrii Meijer. A non-experimental cross-sectional data collection was conducted between April and August 2018 by in-situ observation and measurements on eight ecological factors utilizing thirty-four sampled individual plants in Lojing Highlands, Kelantan, Peninsular Malaysia. The Ordinary Least Squares (OLS) and Heteroscedasticity-ConsistentError (HCE) OLS regression models were employed to establish the statistical relationship between bud's growth and its influencing factors. Host plant's ecological ability, level of temperature, light shading, soil acidity, and interaction between plant survival condition and growth stage were found to be the significant and influential ecological factors to bud's growth of Rafflesia kerrii. The results also showed that, model wise, HCE OLS models outperformed the OLS models in explaining the cause-and-effect relationship under study. Due to some limitations in sampling and data collection, further studies were recommended to corroborate this study using a larger sample covering a larger geographic area - possibly across different localities.
\end{abstract}

\author{
ARTICLE INFO \\ Article history: \\ Received: 22 September 2020 \\ Accepted: 30 December 2020 \\ Published: 30 April 2021 \\ DOI: https://doi.org/10.47836/pjst.29.2.30 \\ E-mail addresses: \\ hamid.m@umk.edu.my (Abdul Hamid Mar Iman) \\ hizami.h@umk.edu.my (Nor Hizami Hassin) \\ azahar.a@umk.edu.my (Muhamad Azahar Abas) \\ zulhazman@umk.edu.my (Zulhazman Hamzah) \\ * Corresponding author
}

Keywords: Bud growth, growth factors, Rafflesia, regression model

\section{INTRODUCTION}

The existence of rare and endangered gigantic plant Rafflesia spp. is geographically limited (Peters \& Ting, 2016). The existing documentation indicates that it is found in 
the lowland and highland of the tropical region of Southeast Asia in Thailand, Indonesia, Malaysia, and the Philippines (Beaman et al., 1998; Jamili, 2001a; Anon, 2003; Balete et al., 2010; Molina et al., 2014; Mahyuni et al., 2015; Mursidawati, 2015; Mursidawati, 2017; Peters \& Ting, 2016; Nery et al., 2016). Even within a particular confine of a country, these species. are a site-specific plant type whose distribution is spatially scarce (Nery et al., 2016). The actual number of varieties of this plant species is still not accurately known. To date, as many as twenty-four (Latiff, 2018), thirty-two (Jumaat et al., 2016); thirty-four (Kedri et al., 2018), forty (Nery et al., 2016), or even fifty-five (Faye, 2008) varieties of Rafflesia species were claimed to have been discovered in the Southeast Asian region with Rafflesia kerrii Meijer being one of them.

Studies on Rafflesia are numerous. Their attractive appearance with large petals, striking red colour, large-hollow perigone lube, smell peculiarity, and parasitic in nature has attracted researchers, local and international alike, on their very nature. However, more aspects of Rafflesia are left to be investigated. Among others, bud growth is a critical aspect for survival of Rafflesia since the plant's abundance depends on bud density per unit area (Qayyum et al., 2012). Factors that influence the plant's distribution directly or indirectly influence the plant's bud growth itself. So far, published works examining the growth performance of Rafflesia 's bud are scanty, and thus, the mystery of the species' bud growth is more to be explored. No description of this variety is given in this paper since not much scientific characterization of it has been documented so far. Nevertheless, some good description of $R$. kerrii can be cited, for example, in Meijer (1984), Jamili (2001a) and Kanchanapoom et al. (2007). The results of this study will partly clarify the conjectural explanation about the factors that contribute to the success of this plant species to survive and develop (Nasihah et al., 2013; Kedri et al., 2018). This study differs from the previous ones since it provides some parametric explanation of the ecological factors hypothesized to be significantly influencing the bud's growth performance of these species, particularly on R. kerrii. Therefore, the objective of this study is to examine the in-situ factors significantly influencing bud's growth (growth in diameter and circumference) of $R$. kerrii by taking a site in Lojing Highlands, Kelantan, Peninsular Malaysia, as a case study.

\section{Literature of Growth Pertinent Aspects of Rafflesia}

In general, a biological organism grows in a particular territorial home called habitat which is ecologically governed by variations in factors such as latitude, altitude/elevation, soils, topography, canopy density, temperature, rainfall, biological interactions with other plants and animals (Martin, 1998). Within a habitat, there is a micro-habitat where temperature, humidity, and light intensity differ in influence from one organism to another (Inger \& Lian, 1996). These are external factors that interact with the very architecture of an organism such as plant species. In this context, the growth aspects of Rafflesia can be studied by their 
biological characterization (physiology, morphology, and phenology) and/or ecological characterization (the external factors) that determine their growth and growth. Each of these options has its specific purpose, methodology and assumptions. Biological characterization studies are reflected in some works such as Barkman et al. (2004), Nickrent et al. (2004), Ramamoorthy et al. (2013), Jumaat et al. (2016), Latifah et al. (2017), and Chu et al. (2018). In the current study, attention is given more on the ecological factors of $R$. kerrii.

Climatic factors (e.g. rainfall, humidity, wind, gases, temperature, light); edaphic/ physiographic factors (e.g. relief, altitude/elevation, aspect, exposure, slope, niche); soil factors (e.g. structure, texture, nutrients, acidity); and biotic factors (e.g. interrelationship between organisms) are all the ecological factors that determine the growth and growth of plant species in general (Beaman et al., 1988; Bareja, 2011; Kumar, 2018). In particular, factors influencing the growth of Rafflesia species are very intricate and, so far, no studies have provided a satisfactory explanation on the factors that significantly determine the plant's growth success (Mursidawati, 2017). Out of such factors, there are some specific factors operating in-situ that have different degrees of influence and importance to Rafflesia. Further, there are some anomalies to these that are not easy to explain without a carefully designed quasi-experimental study. For example, Rafflesia species are not mainly influenced by soils since they can grow on various substrates (Jamili, 2001a). Rafflesia species are also a dioecious plant type (i.e., separate male and female flowers), with only a few colonies in a designated area, are mostly male while males and females rarely bloom at the same time; these factors contribute to the difficulty in their multiplication (Salleh, 2007; Balete et al., 2010; Susatya, 2011). It was also said that Rafflesia species have some specialized habitat where there is water abundance (river banks), close to bamboo clumps, dependent upon the distribution and characteristics (e.g. size and ability) of the host plants, endemic to different geographic locations, and grows at higher altitudes (Faye, 2008; Akhriadi et al., 2010; Galindon et al., 2016). Rafflesia species are known to be a site-specific plant type, and their propagation ex-situ is very difficult (Jamili, 2001a, Jamili, 2001b; Mursidawati \& Risawati, 2009; Wicaksono \& Da Silva, 2015). Scanty information on the in-situ and ex-situ factors believed to be influencing the plant's growth can be scanned through the existing body of knowledge.

However, many of these factors were studied in isolation, making the result conjectural in nature. An important characteristic of Rafflesia species is that they are holoparasites growing on vine's root tissues, such as Tetrastigma leucostaphyllum and T. scariosum (Veldkamp, 2009; Susatya, 2011). Therefore, edaphically, Rafflesia species can be found at sites where these host plants are distributed. Further, factors affecting Tetrastigma will directly affect Rafflesia although the relationships between these two partners are still poorly understood (Mursidawati, 2017). All these points to the need for some comprehensive studies on Rafflesia covering all of their growth factors in-situ. 
Not much has been researched about Rafflesia's bud growth from its dormancy, burst moment to flowering phases. Rafflesia undergoes nine-phase growth of which bud growth occurs in the third and fourth phases (Jamili, 2001b). During this period, pertinent in-situ factors operate to determine the growth of bud. Bud erupts from an infected host vine, swells slowly over months - usually four to nine - to the size of cabbages (Shaw, 2017; Latiff, 2018) and blooms into flower especially in the rainy season depending on the presence of large bud (Jumaat et al., 2016). Since Rafflesia has no leaves, stems, and chlorophyll, making them incapable of photosynthesis, the bud grows by living off the host plant's vine, draining water and nutrients from it for six to nine months before reaching the flowering phase. Since Rafflesia grows predominantly on vine's root, host plant's root density around a particular site is an important factor that encourages the production of bud, directly or indirectly. With Rafflesia species totally depend on their host plants for water and food, soil nutrients and soil acidity could be other factors directly influencing bud's growth. Besides, elevation/altitude which, in turn, indirectly determines other physical factors such as canopy shade, air temperature, humidity, and wind speed can also influence Rafflesia's bud growth.

However, so far, the ecological factors influencing Rafflesia's bud growth are yet to be statistically quantified. Such a study is vital to examine factors that might be statistically significant to the plant species' growth. More of such study is necessary to ascertain whether the relationship between plant growth and its determining factors is geographically and functionally stable. It is also important to ensure that while studies on Rafflesia's biological characteristics are necessary, exploring their ecological characteristics is equally important.

\section{MATERIALS AND METHODS}

\section{Study Area}

Lojing is a highland area located in Gua Musang, Kelantan, Peninsular Malaysia, bordering Cameroon Highland, Pahang, on the eastern side (Figure 1a). It is popular for highland agriculture as well as one of the prime hotspots for $R$. kerrii in Malaysia. Ironically, $R$. kerrii had become an icon for conservation and a flagship of tourist destination to Lojing Highland.

\section{Data Collection}

A forest tract of about 3-ha. where $R$. kerrii thrived was selected for data collection. We adopted a non-experimental cross-sectional study with data collection conducted between April and August 2018 with the site being visited five times. A total of thirty-four individual plants were selected from a population of Rafflesia spp. that randomly distributed over the study area. The decision to have picked only thirty-four individual plants was made due to time and resource constraints. However, a sufficiently minimal sample size was managed 
to be collected for the statistical analysis. Inspection proceeded in a linear traverse mode starting at the southwest corner of the study area where two baselines intersected (Figure 1b). One of the baselines was selected quite parallel to the main road, some $250 \mathrm{~m}$ away from it. Using a digital compass and Global Positioning System (GPS) device, each plant's site geo-coordinates were recorded for easy identification, systematic data records, and to avoid repeated data collection of the same spot. As we walked along each of the linear lines, we selected the Rafflesia plant, limiting it to 4-6 individuals, over a 25-m wide swath to the right of each traverse line. Data on the pertinent factors influencing plant growth were collected by in-situ observation and measurements where $R$. kerrii was found.

Site elevation/altitude was measured using a high-resolution real-time kinematic global positioning system device; for double-checking purposes, a topography map of the study area was also used. The temperature and humidity levels were measured using ThermoPro TP53 hygrometer humidity gauge. Light shading measurement was made by a modified "visible sky" approach (i.e. visible sky x $100=\%$ canopy openness) as per Montgomery (2004). In this approach, light shading $(\%)=(100$ - canopy openness $) \%$. It was found that canopy openness ranged between $13 \%$ to $29 \%$. We followed Kedri et al. (2018) in classifying the growth stages of $R$. kerrii into stages I, II, or III. Each individual plant was roughly observed by assessing the morphological features of the flower bud $(1=$ if stages II or III; $0=$ if stage I). The full description for assessing growth-stage morphology is contained in Jamili (2001b). The plant survival condition was roughly assessed by

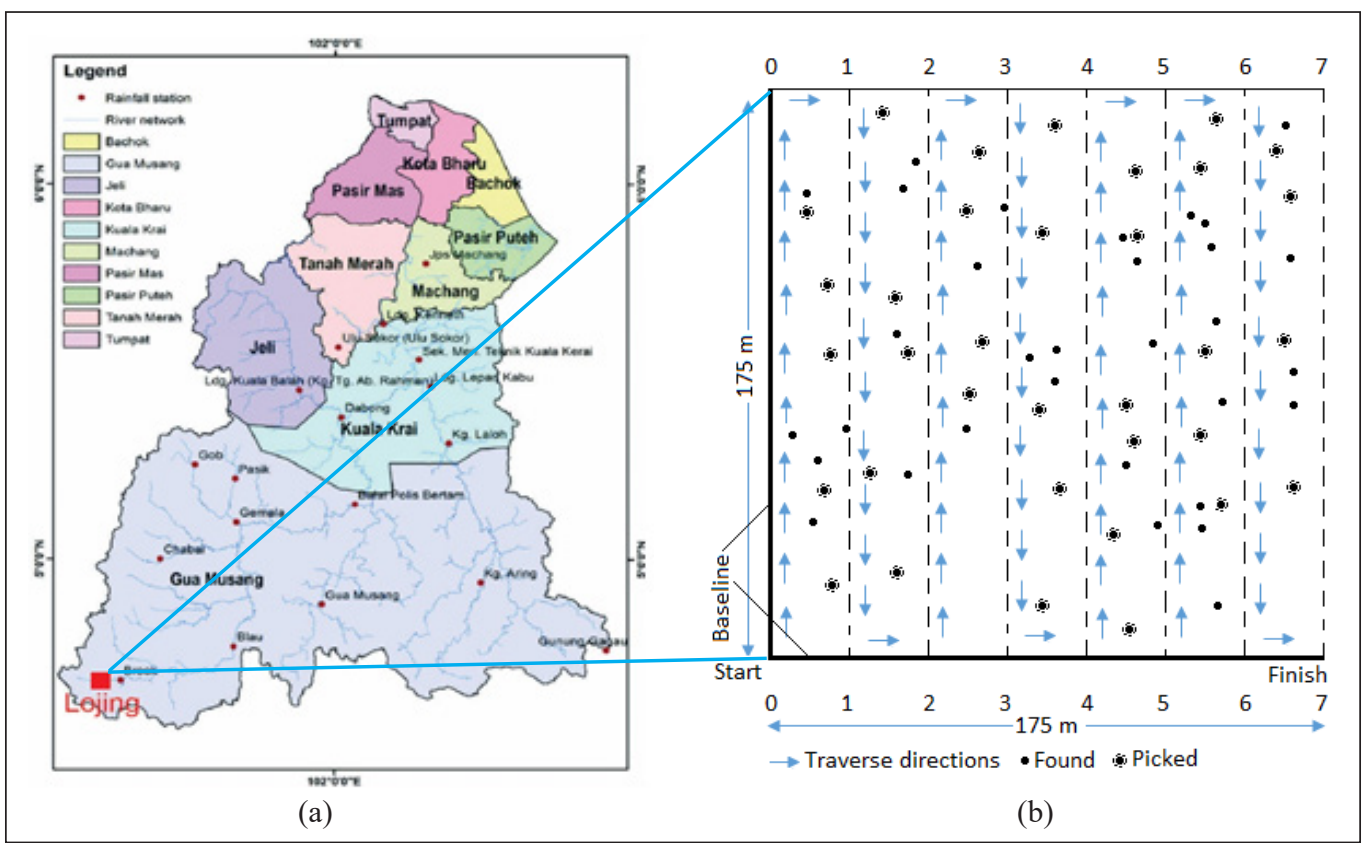

Figure 1. Location of the study area and sampling design 
considering as to whether a particular individual plant was still alive or already dead/ dying ( $1=$ if alive; $0=$ if dead/dying) during the fieldwork. A handy soil $\mathrm{pH}$ meter was used to detect the level of soil acidity measured at the base of the host plant. Although the data may not be as accurate as those obtained from a laboratory test, the purpose was to give an indicative state of in-situ soil acidity. Soil acidity was assumed to be directly related to soil's nutrient contents; a lower-level acidity (higher $\mathrm{pH}$ value) corresponds to a richer amount of nutrients. It was not accurately known as to the ideal level of soil acidity for Rafflesia, but the level of pH of 5.0-5.5 was perceived to be ideal for the plant's good growth performance. Bud growth was measured by its diameter (and circumference) as per Faust and Lewis (2005), using a measuring tape.

\section{Data Analysis}

Modelling Growth Factors. Factors that influence the growth of Rafflesia could not be explained satisfactorily without designing a sample for data collection, especially for parametric analysis. A sufficiently large geographic area across a country or a region may be necessary to ascertain the ecological characteristics of Rafflesia where the growthinfluencing factors operate systematically such as the distribution and conditions of host plants Tetrastigma species., male-female bloom lag; canopy shading, growth stage and survival condition (Beaman et al., 1988; Jamili \& Wilcock, 1998; Jamili et al., 2000; Jamili, 2001a, Jamili, 2001b; Akhriadi et al., 2010; Kedri et al., 2018). Unfortunately, within a small forest tract (say, a 3-ha. plot) and over a short period of study, only a limited number of factors could be studied ensuring, nonetheless, that there is a sufficient random variation of these factors in influencing the growth of the plant.

Given the array of growth factors, as mentioned earlier, statistical modelling is an objective way of simultaneous consideration of these factors for a parametric analysis under the assumptions of best linear unbiased estimates (BLUE). Since not all factors can be specified in a model, a statistical model will usually prescribe a limited number of pertinent factors. Given this premise, a parsimonious statistical relationship of Rafflesia against the pertinent in-situ growth factors must be established. Partial relationships between the growth of this plant species against its influencing factors such as host plant, soil, etc. have been described in several studies (Nasihah et al., 2013; Nasihah et al., 2016). However, due to such partial analyses, in most situations, the claimed relationship between Rafflesia and their growth-influencing factors was rather conjectural.

Despite the studies examining the habitat of Rafflesia (Faye, 2008; Hidayati \& Walck, 2016; Kedri et al., 2018) there was no parametric analysis of factors that may significantly influence the plant's bud growth. In Faye (2008) study on Rafflesia keithii, canopy cover, temperature, and vegetation were studied. A variety of statistical models for evaluating 
various issues on bud growth were employed in a number of studies where temperature and photoperiod were two main factors specified in the models (Osawa et al., 1983; Kramer, 1994; Hakkinen et al., 1998; Hakkinen, 1999; Mello \& Tuan, 1999; Linksolo et al., 2000). However, none of these studies was investigating parasitic plants. Studies on parasite-host relationships were focused mainly on agricultural crops (e.g. Grenz et al., 2005; Moreau et al., 2016). Apart from Rafflesia works on parasitic plants can be cited in a limited number of studies (Medel, 2000; Hautier et al., 2010). Again, however, these studies were either non-statistical or based on controlled experiments and not focusing on bud growth. The current study is focusing on a non-experimental parasitic plant, i.e. R. kerrii Meijer whose bud growth is hypothesized to be influenced by its ecological factors and whose data are to be collected by cross-sectional in-situ observation and site measurements.

Basic Postulation of the Model. Plant growth is a fundamental ecological process with a variety of reasons for its growth and functional in nature (Paine et al., 2012). With a parsimonious statistical relationship, a group of ecological factors - physical and environmental - can be considered simultaneously by a regression model and, thus, the partial contribution of each factor on the plant's growth performance can be assessed more objectively. As found in the body of literature on statistical modelling, a parsimonious statistical relationship between a growth variable and its growth-influencing factors can be specified in general as Equation 1:

$$
\mathrm{Y}=\mathrm{X} \beta+\varepsilon
$$

where $\mathrm{Y}=(\mathrm{n} \times 1)$ matrix of dependent variable (e.g. bud diameter/circumference); $\mathrm{X}=(\mathrm{n} \times \mathrm{k})$ matrix of independent ecological variables (physical and environmental); $\beta$ $=(\mathrm{k} \times 1)$ matrix of regression parameters, including the intercept; and $\varepsilon=(\mathrm{nx} 1)$ matrix of error term. In a parsimonious statistical relationship, we are interested to quantify the regression parameter, $\beta$, which is derived by a matrix manipulation as Equation 2 (ignoring $\varepsilon$, for simplicity):

$$
\beta=\left(X^{\prime} X\right)^{-1} X^{\prime} Y
$$

Functionally, $\beta$ is equivalent to the marginal effect of $\mathrm{X}$ on $\mathrm{Y}$, i.e. $\beta=\delta \mathrm{Y} / \delta \mathrm{X}$ for a linear model. In other words, the marginal effect of a physical and environmental factor is quantified by the differentiation of the regression equation. In this context, our interest is to test the hypothesis (at $\alpha=0.05$ and better) as follows: $\mathrm{H}_{0}: \beta_{1}, \beta_{2}, \ldots, \beta_{\mathrm{k}}=0$ against $\mathrm{H}_{1}: \beta$ 's $\neq$ 0 at least for one factor. As with our case study, the general relationship between Rafflesia's growth performance and the growth factors can be specified as Equation 3a and $3 \mathrm{~b}$ : 


$$
\begin{aligned}
\frac{D I A M^{\lambda_{1}}-1}{\lambda_{1}}= & \alpha+\beta_{1}\left(\frac{E L E^{\lambda_{2}}-1}{\lambda_{2}}\right)+\beta_{2}\left(\frac{T E M P^{\lambda_{2}}-1}{\lambda_{2}}\right)+\beta_{3}\left(\frac{S H A D E^{\lambda_{2}}-1}{\lambda_{2}}\right) \\
& +\beta_{4}\left(\frac{H U M I D^{\lambda_{2}-1}}{\lambda_{2}}\right)+\beta_{5}\left(\frac{P H^{\lambda_{2}-1}}{\lambda_{2}}\right)+\beta_{6}\left(\frac{R O O T S^{\lambda_{2}-1}}{\lambda_{2}}\right)+\beta_{7} T E R M I T \\
& +\beta_{8} C O N D+\beta_{9} S T A G E+\varepsilon \\
\frac{C I R C M^{\lambda_{1}}-1}{\lambda_{1}}= & \gamma+\varphi_{1}\left(\frac{E L E^{\lambda_{2}}-1}{\lambda_{2}}\right)+\varphi_{2}\left(\frac{T E M P^{\lambda_{2}}-1}{\lambda_{2}}\right)+\varphi_{3}\left(\frac{S H A D E^{\lambda_{2}}-1}{\lambda_{2}}\right) \\
& +\varphi_{4}\left(\frac{H U M I D^{\lambda_{2}}}{\lambda_{2}}\right)+\varphi_{5}\left(\frac{P H^{\lambda_{2}-1}}{\lambda_{2}}\right)+\varphi_{6}\left(\frac{R O O T S^{\lambda_{2}-1}}{\lambda_{2}}\right)+\varphi_{7} T E R M I T \\
& +\varphi_{8} C O N D+\varphi_{9} S T A G E+\varepsilon
\end{aligned}
$$

where DIAM = Rafflesia flower's bud diameter $(\mathrm{cm})$; CIRCUM = Rafflesia flower's bud circumference $(\mathrm{cm})$; ELEV = elevation above mean sea level $(\mathrm{m})$; TEM = level of temperature $\left({ }^{\circ} \mathrm{C}\right)$; SHADE = light shading/intensity (100-\% of light penetration); HUMI $=$ level of humidity $(\%) ; \mathrm{pH}=$ soil acidity at the host plant's base $(0-14) ; \mathrm{ROOT}=$ number of visible Tetrastigma's roots/vines on ground surface within a 20-m radius; TERMITE = presence of termites on the plant $(1=$ yes; $0=$ no $)$; COND $=$ state of survival $(1=$ alive; dead $=0)$; STAGE $=$ growth stage at time of inspection $(\mathrm{I}, \mathrm{II}, \mathrm{III}) ; \alpha, \gamma, \beta \mathrm{s}, \varphi \mathrm{s}$ are regression coefficients, $\varepsilon$ is error term, (.) $\lambda_{1}$ and (.) $\lambda_{2}$ are the Box-Cox transformations of the variables over a range of values of $\lambda_{1}$ and $\lambda_{2}$.

Equation $3 \mathrm{a}$ and $3 \mathrm{~b}$ are specified because, in theory, plant growth performance is not likely to be influenced by its growth factors linearly (Koya \& Ghosu, 2013). The body of literature on plant growth has indicated rather non-linear relationships between these two sets of factors. It follows that model's functional forms need to be tested on a case by case basis. In this context, different values of $\lambda$ can be chosen for the dependent and continuous explanatory variables. However, to avoid the estimation becoming too cumbersome, it is assumed that $\lambda$ is equal for all variables (Greene, 1990). Maddala (1977) pointed out that the search procedure for the optimal regression model would not be efficient if there were more than two or three $\lambda$ 's. Considering all these points, therefore, the same value of $\lambda$ was chosen for the above model, that is, $\lambda 1=\lambda 2=\lambda$. In general, the Box-Cox transformation indicates whether the model to which the data will best fit is a linear or non-linear model. The Box-Cox transformation, however, has one major caveat: the optimum equation (one with the smallest SSE, MSE, or RMSE) may not produce a model that can be easily used for estimating the effects of attributes (Milon et al., 1984). This occurs when the optimum 
equation results in the Box-Cox parameter, $\lambda 1$ or $\lambda 2$ such that $0>(\lambda 1, \lambda 2)>1$, for the dependent variable. Furthermore, parameter estimates tend not to be stable, that is, they are susceptible to the inclusion of other variables in the regression equation. Therefore, the choice of model for estimating these effects is normally confined to the special cases of Box-Cox functions. In this context, if $\lambda 1=\lambda 2=1$, Equation 5 is linear; if $\lambda 1=\lambda 2=0$, it is double $\log$; if $\lambda 1=1$ and $\lambda 2=0$, it is linear-log; and if $\lambda 1=0$ and $\lambda 2=1$, it is log-linear. In these special cases, the choice of best function is determined primarily by the standard statistical tests, two of which are the likelihood ratio test (Griffith et al., 1993; Maddala, 1992) and the Box-Cox test for model equivalence (Greene, 1990). However, the adjusted $\mathrm{R} 2$ and F-value are consistent with these two measures so that in most cases, they can be used to compare between models.

Some modification in the modelling is proposed. First, variable manipulation necessitates creating a new variable CONSTA $=$ COND x STAGE. By assumption, growth stage and growth condition are interactive in terms of plant survival and performance. For instance, bud-stage growth will only be meaningful if the plant is alive while, in the same way, plant stage is important to give rise to plant survival condition. In particular, the chances of survival are considered higher if the plant reaches advanced stages of growth. Second, the effects of growth factors on the plant's growth performance can be expected to differ functionally.

Heteroscedasticity-Consistent-Error (HCE) OLS. Cross-sectional ecological data on plant growth may be subjected to heteroscedasticity due to changing variable interactions across a particular study area. For instance, there may be changing relationships of $\mathrm{pH}$ nutrient, temperature-shade, temperature-humidity, etc. at different elevations. When modelled, such phenomena will give rise to the violation of OLS assumptions that $\operatorname{var}\left(\varepsilon_{\mathrm{i}} \mid \mathrm{X}_{\mathrm{i}}\right)$ $=0$ for all $\mathrm{i}$ and $\mathrm{E}\left(\varepsilon_{\mathrm{i}} \varepsilon_{\mathrm{j}}\right)=0$. When the assumptions of constant-variance and uncorrelated errors of a regression model are violated, the errors will be heteroscedastic, resulting in the non-minimum mean square error (MSE) of OLS estimator and inconsistent estimator for the variance of OLS estimates (Wikipedia, 2018). OLS estimates will also become inefficient while the estimated standard errors can be either too large or too small (Long \& Ervin, 1998). Given that heteroscedasticity is a common problem in cross-sectional data analysis, corrective methods are important for prudent data analysis. This is solved by estimating a heteroscedasticity-consistent-error (HCE) model that will result in a statistically better model in terms of corrected regression-error estimates and higher degrees of variation in the dependent variable is explained.

From Equation 1, the $\mathrm{i}^{\text {th. }}$ row of $\mathrm{X}$ can be written as Equation 4

$$
\mathrm{y}_{\mathrm{i}}=\mathrm{x}_{\mathrm{i}} \beta+\varepsilon_{\mathrm{i}}
$$


With all BLUE assumptions being satisfied, the OLS estimator $\hat{\beta}=\left(X^{\prime} X\right)^{-1} X^{\prime} y$ has the covariance matrix as in Equation 5

$$
\operatorname{Var}(\hat{\beta})=\left(\mathrm{X}^{\prime} \mathrm{X}\right)^{-1} \mathrm{X}^{\prime} \Phi \mathrm{X}\left(\mathrm{X}^{\prime} \mathrm{X}\right)^{-1}
$$

where $\Phi$ is a diagonal matrix with $\phi_{i i}=\operatorname{var}\left(\varepsilon_{i}\right)$. It can be proven that if the errors are homoscedastic, i.e. $\Phi=\sigma^{2}$ I, Equation 5 becomes Equation 6

$$
\begin{aligned}
\operatorname{Var}(\hat{\beta}) & =\left(\mathrm{X}^{\prime} \mathrm{X}\right)^{-1} \mathrm{X}^{\prime}\left(\sigma^{2} \mathrm{I}\right) \mathrm{X}\left(\mathrm{X}^{\prime} \mathrm{X}\right)^{-1} \\
& =\sigma^{2}\left(\mathrm{X}^{\prime} \mathrm{X}\right)^{-1} \mathrm{X}^{\prime} \mathrm{X}\left(\mathrm{X}^{\prime} \mathrm{X}\right)^{-1} \\
& =\sigma^{2}\left(\mathrm{X}^{\prime} \mathrm{X}\right)^{-1}
\end{aligned}
$$

where $\sigma^{2}$ is dependent variable's variance. Defining the residuals as $e_{i}=\mathrm{y}_{i}-\mathrm{x}_{i} \hat{\beta}$, the usual OLS covariance matrix, OLSCM, can be estimated as Equation 7

$$
\mathrm{OLSCM}=\frac{\sum e_{i}^{2}}{N-K}\left(\mathrm{X}^{\prime} \mathrm{X}\right)^{-1}=\sigma^{2}\left(\mathrm{X}^{\prime} \mathrm{X}\right)^{-1}
$$

If the errors are heteroscedastic, OLSCM will be biased and the usual tests of statistical significance will be inconsistent. Since the form of heteroscedasticity is rarely known, we need a consistent estimator $\Phi$ in order to apply Equation 5. This is done by creating a heteroscedasticity consistent covariance matrix (HCCM) and a model having it is a heteroscedastic-corrected-error (HCE) OLS. Assuming that $e_{i}^{2}$ can be used to estimate $\phi_{i i}$, let $\widehat{\Phi}=\operatorname{diag}\left[e_{i}^{2}\right]$, resulting in an estimator called $\mathrm{HC} 0$ as Equation 8

$$
\begin{aligned}
\mathrm{HC} 0 & =\left(\mathrm{X}^{\prime} \mathrm{X}\right)^{-1} \mathrm{X} \widehat{\Phi} \mathrm{X}\left(\mathrm{X}^{\prime} \mathrm{X}\right)^{-1} \\
& =\left(\mathrm{X}^{\prime} \mathrm{X}\right)^{-1} \mathrm{X}^{\prime} \operatorname{diag}\left[e_{i}^{2}\right] \mathrm{X}\left(\mathrm{X}^{\prime} \mathrm{X}\right)^{-1}
\end{aligned}
$$

In Equation 8, $\widehat{\Phi}$ is estimated based on OLS residuals, $e$, which may not likely be homoscedastic. If $h_{i i}=\mathrm{x}_{i}\left(\mathrm{X}^{\prime} \mathrm{X}\right)^{-1} \mathrm{X}_{i}$, then $\operatorname{Var}\left(e_{i}\right)=\sigma^{2}\left(1-\mathrm{h}_{i i}\right) \neq \sigma^{2}$. According to Belsley et al. (1980), since $0 \leq \mathrm{h}_{i i} \leq 1, \operatorname{Var}\left(e_{i}\right)$ tends to underestimate $\sigma^{2}$. Further, since $\operatorname{Var}\left(e_{i}\right)$ varies across observations, the OLS residuals will tend to be heteroscedastic too. Hinkley (1977) suggests inflating $e_{i}$ by $\sqrt{N /(N-K)}$, where $\mathrm{N}=$ sample size and $\mathrm{K}=$ number of regression parameters, for 'correcting' Equation 8. But, since $e_{i}{ }^{2}$ is still a biased estimator for $\sigma^{2}$, weighing Equation 7 by $\mathrm{e}_{i}^{2} /\left(1-\mathrm{h}_{\mathrm{ii}}\right)$ or by $\mathrm{e}_{i}^{2} /\left(1-\mathrm{h}_{\mathrm{ii}}\right)^{2}$ will produce a less biased estimator. Without a further elaboration here, the literature suggests three variants of 'corrected' Equation 8 as Equation 9a, 9b and 9c (Hinkley, 1977; MacKinnon \& White, 1985): 


$$
\begin{aligned}
& \mathrm{HC} 1=\frac{N}{N-K}\left(\mathrm{X}^{\prime} \mathrm{X}\right)^{-1} \mathrm{X} \operatorname{diag}\left[e_{i}^{2}\right] \mathrm{X}\left(\mathrm{X}^{\prime} \mathrm{X}\right)^{-1} \\
& \mathrm{HC} 2=\frac{N}{N-K}\left(\mathrm{X}^{\prime} \mathrm{X}\right)^{-1} \mathrm{X} \operatorname{diag}\left[\frac{e_{i}^{2}}{1-h_{i i}}\right] \mathrm{X}\left(\mathrm{X}^{\prime} \mathrm{X}\right)^{-1} \\
& \mathrm{HC} 3=\frac{N}{N-K}\left(\mathrm{X}^{\prime} \mathrm{X}\right)^{-1} \mathrm{X} \operatorname{diag}\left[\frac{e_{i}^{2}}{\left(1-h_{i i}\right)^{2}}\right] \mathrm{X}\left(\mathrm{X}^{\prime} \mathrm{X}\right)^{-1}
\end{aligned}
$$

The default in Gretl software - the one used in this paper - is HCO but it also includes the other options under a number of modeling choices, namely: (a) Model $\rightarrow$ Ordinary Least Squares $\rightarrow$ Robust standard errors (HC1); (b) Model $\rightarrow$ Instrumental variables $\rightarrow$ TwoStage Least Squares $\rightarrow$ Robust standard errors (HC1); (c) Model $\rightarrow$ Other linear models $\rightarrow$ Weighted Least Squares $\rightarrow$ Robust standard errors (HC1); (d) Model $\rightarrow$ Other linear models $\rightarrow$ Heteroscedasticity corrected (presumably HC1); (e) by gretl scripting option; (f) by specifying either HC1, HC2, or HC3 in the main menu bar: Tools $\rightarrow$ Preferences $\rightarrow$ General $\rightarrow$ HCCME); there we can select from a set of possible robust estimation variants, and can also choose to make robust estimation the default (Cottrell \& Luccetthi, 2005). In this paper, option (d) was selected.

\section{RESULT AND DISCUSSIONS}

\section{Sample Profile}

The profile of 34 individual sampled $R$. kerrii plants in the study area is presented in the form of a sample's descriptive statistics (Table 1) and variables' partial correlations (Table 2). Based on Table 1, the average altitude (ELEV) of the study plot was 1,044.03 $\mathrm{m}$ from the mean sea level with an average temperature (TEM) of $25.21^{\circ} \mathrm{C}$. The study plot had a minimum-maximum difference of $28 \mathrm{~m}$ in elevation and of $0.55^{\circ} \mathrm{C}$ in temperature, which was rather large for a small-range vertical height. Still, the temperature difference could have also been interacting with in-situ air humidity (HUMI) and light shading (SHADE). This can be examined from the variables' partial correlations, $\rho$, namely TEM vs. HUMI, TEM vs SHADE, and TEM vs ELEV (Table 2$)$. A low negative correlation $(\rho=-0.47)$ occurred to in-situ TEM vs. ELEV and to TEM vs. HUMI $(\rho=-0.40)$ while a high negative correlation occurred to TEM vs. SHADE ( $\rho=-0.75)$. In general, a lower temperature coexisted with a higher light shading, air humidity and elevation.

The average humidity was $85.18 \%$ while the moderate light shading under the canopy was $79.32 \%$. However, the low-level correlations between TEM and HUMI; TEM and ELEV; and ELEV and SHADE were likely to be affected by other physical or environmental factors. For instance, forest clearing at higher altitudes or the global warming that increased the outer environment's temperature could have reduced the co-existing effects of these factors (Saxe et al., 2001). The soils in the study area have an average acidity of 4.84 on 
Abdul Hamid Mar Iman, Nor Hizami Hassin, Muhamad Azahar Abas and Zulhazman Hamzah

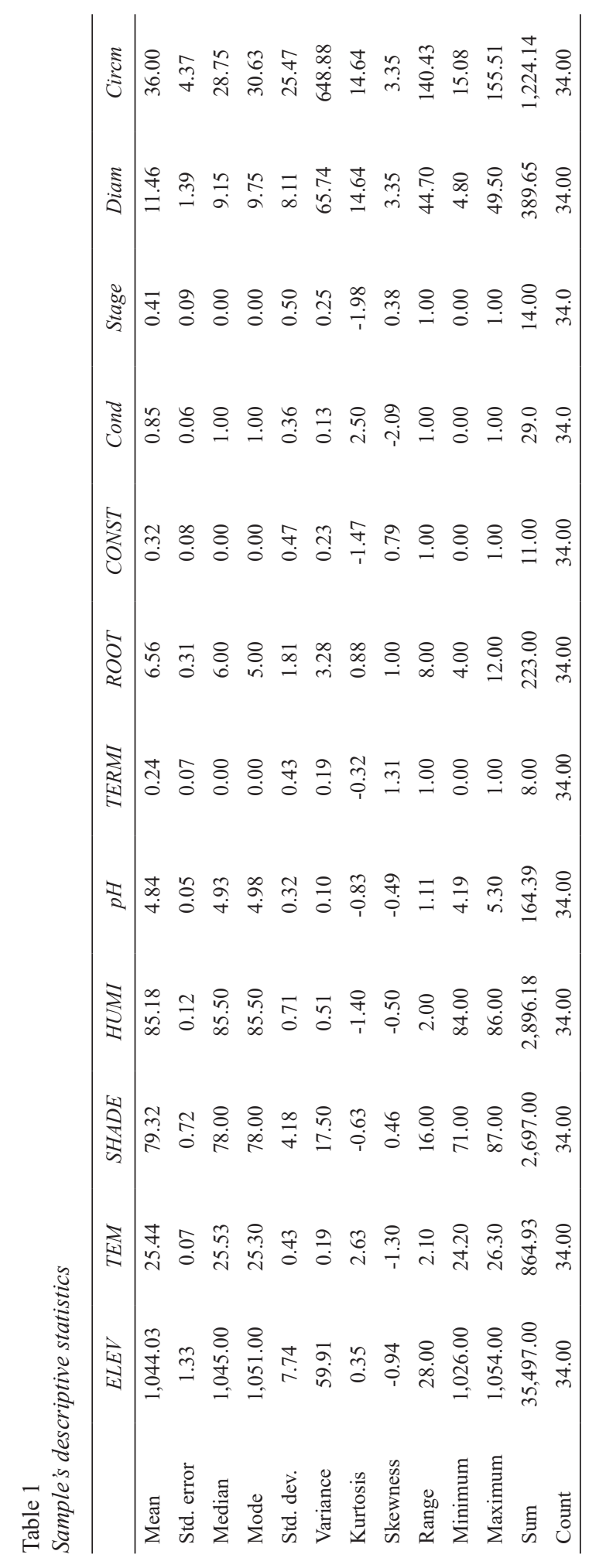


Modelling In-situ Factors Affecting Bud's Growth of Rafflesia kerrii Meijer

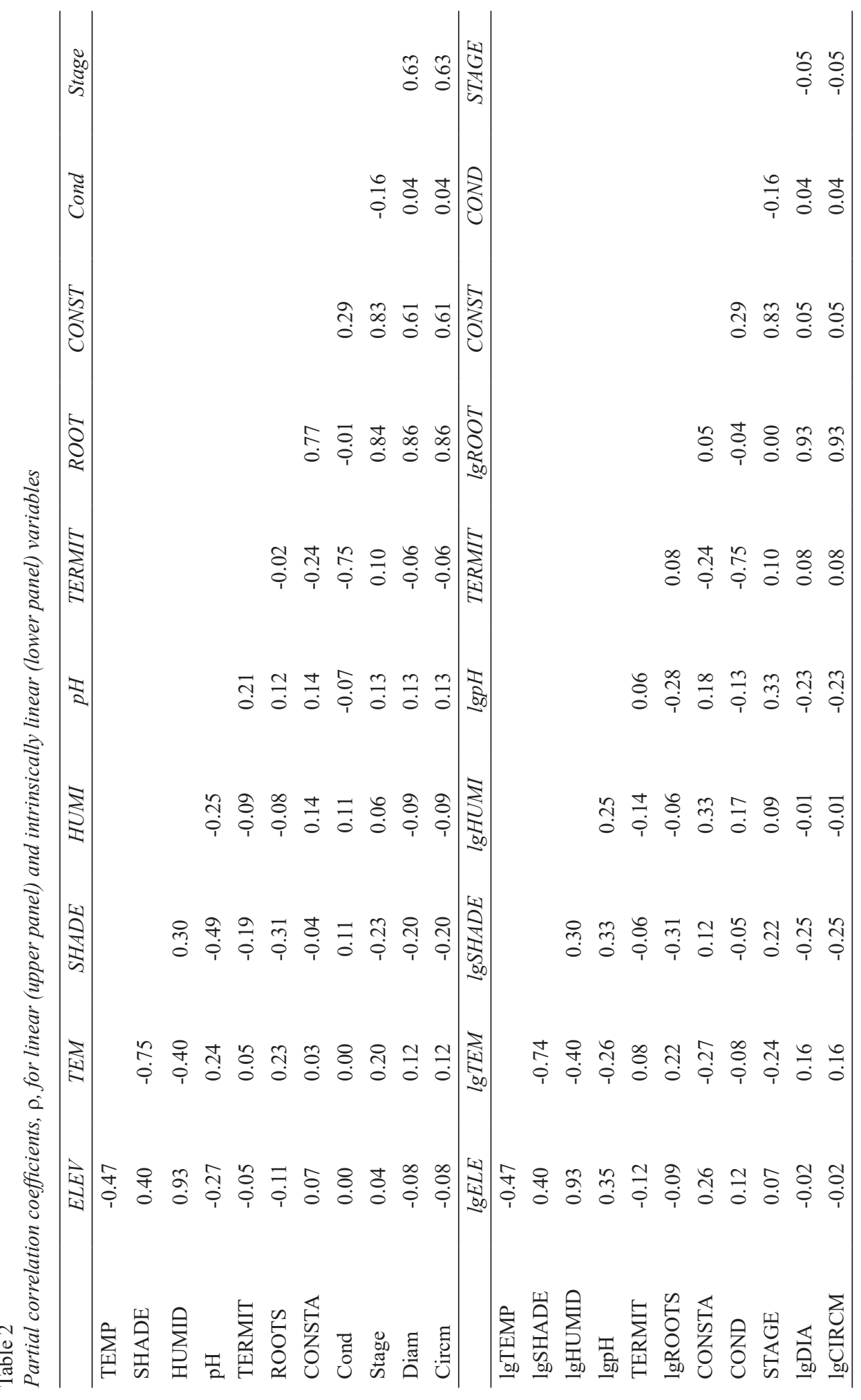


the $\mathrm{pH}$ scale. This is considered good for the proliferation of Rafflesia. In spite of that, Table 2 shows that the effects of soil acidity have a low overall co-existence with the effects of other ecological factors in the environment. Other than that, as much as $24 \%$ of the sampled $R$. kerrii 's flower was infested by termites whereby they strongly co-existed with stages II and III (advanced stages) of plant growth.

This was quite logical because the organisms could have scavenged for foods and shelter on a more matured plant compared to a younger plant. On average, each host plant of Tetrastigma has about 6-7 visible roots/vines above the soil surface to enable infestation by the $R$. kerrii. Closely related to this was the $32 \%$ average proportion of individual plants growing at stages II and III that were alive (indicated by the variable CONST). Further, CONST was positively highly correlated with STAGE (Table 2) and was quite highly correlated with linear bud diameter (DIAM) and circumference (CIRCM). Bud diameter and circumference were highly positively correlated $(\rho=0.84-0.93)$ with the number of host plant's visible roots/vines above the ground surface within a $20-\mathrm{m}$ radius around the host plant's base (ROOT). A quite strong positive correlation $(\rho=0.77)$ also occurred between the interacting growth status and growth stage (CONST) and ROOT in the linear data.

Comparing the upper and lower panels of Table 2, it is obvious that serious multicollinearity existed among variables in their linear form; the problem was much reduced in the intrinsically linear form. It signals to two important aspects. First, individual variables' partial relationships were not likely to be linear. Second, the appropriate statistical model was not likely to be linear in its functional form, rather, it needs to be intrinsically linear or non-linear. In this study, however, lower-power functional forms were tested on the basis of the theoretical background already discussed before which necessitated the Box-Cox variable transformation and intrinsically linear model specification.

\section{Modelling Results}

To economize space and discussion, only the results for bud diameter (DIAM) analysis are reported in this paper. The parametric effects of the eight specified ecological factors on the growth of both plant's bud diameter and circumference were largely symmetrical despite differences in figures and, therefore, the outputs for bud circumference are displayed only for comparison purposes. The smaller log-likelihood ratio, larger $\mathrm{R}^{2}$, larger adj. $\mathrm{R}^{2}$, larger F-value, and smaller standard error of regression indicates that the heteroscedasticitycorrected-error models (HCE OLS) were better than the ordinary least squares (OLS) models while on the basis of larger individual $\mathrm{R}^{2}$ and larger adjusted $\mathrm{R}^{2}$, the $\log$-log model slightly outperformed other models (Table $3 \& 4$ ). However, by considering all criteria, including the explanatory aspect (number of statistically significant factors), the lin-log model $\left(\lambda_{1}=1, \lambda_{2}=0\right)$ was the best model to relate $R$. kerrii's bud growth against its pertinent ecological factors. On the basis of this model, about $94 \%$ variation in bud growth (i.e. 
Modelling In-situ Factors Affecting Bud's Growth of Rafflesia kerrii Meijer

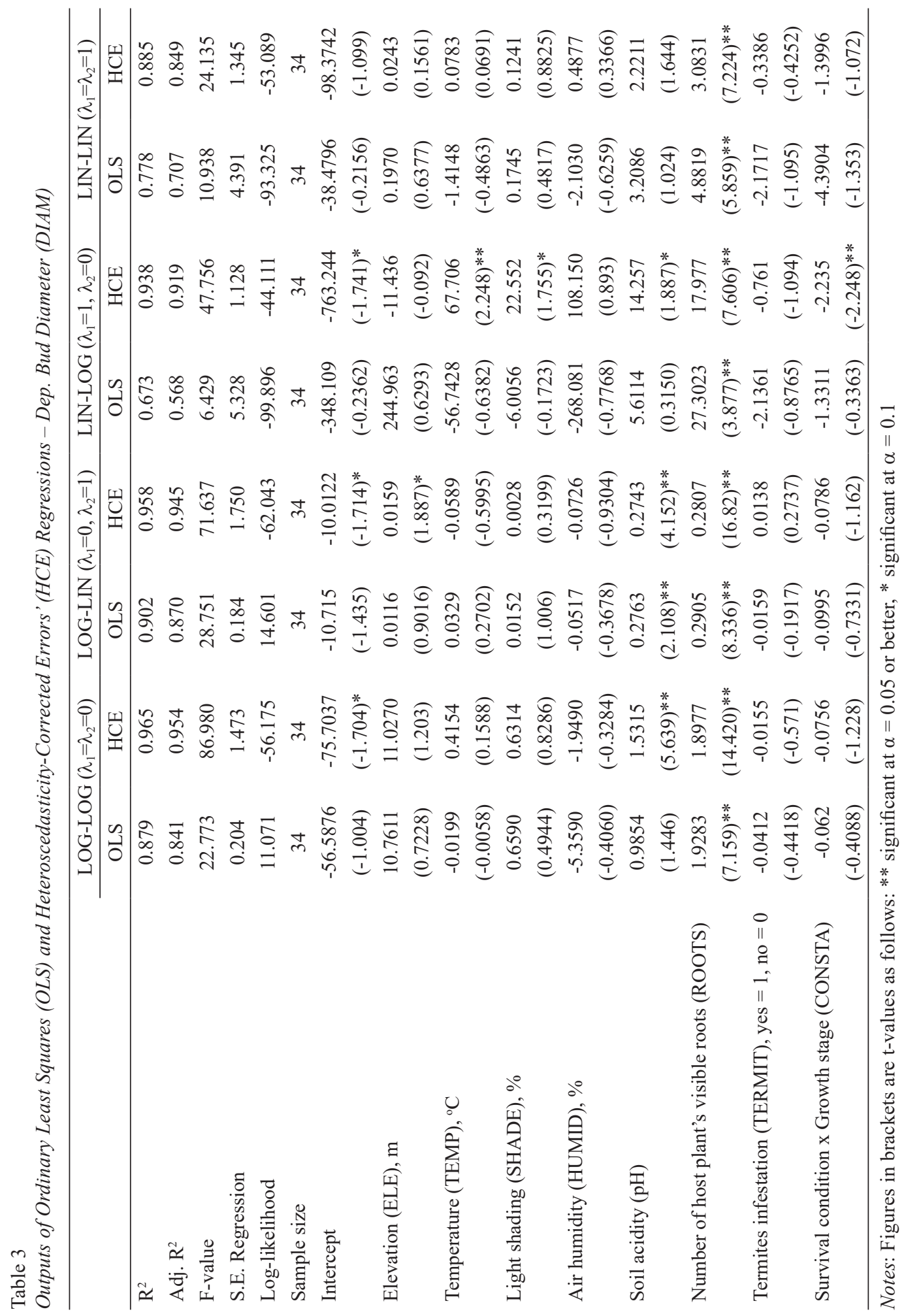


Abdul Hamid Mar Iman, Nor Hizami Hassin, Muhamad Azahar Abas and Zulhazman Hamzah

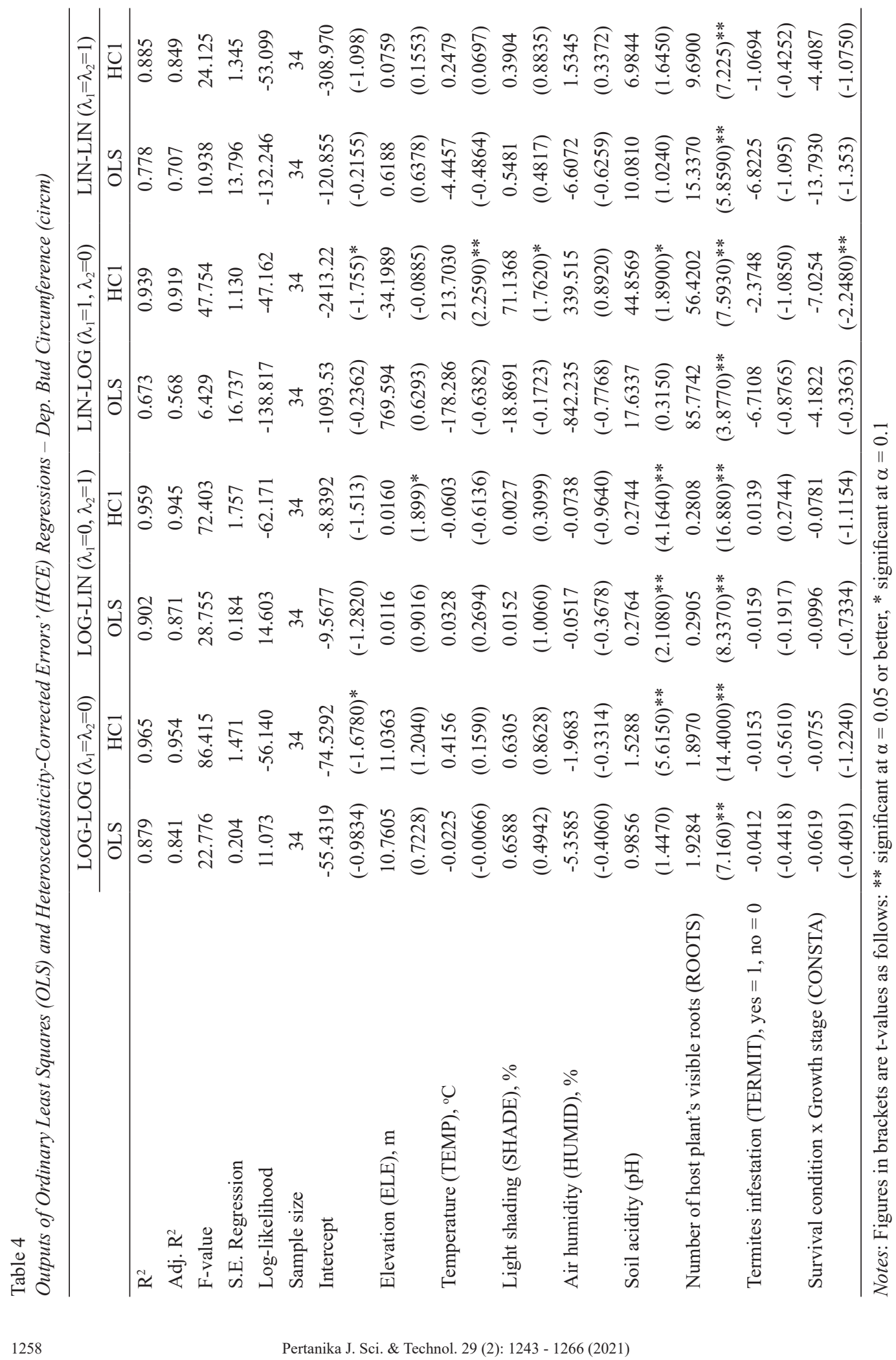


growth in diameter and circumference) in $R$. kerrii was explained by the eight specified ecological factors leaving about $6 \%$ variation in the species' growth remained unexplained by the model.

Other factors that could have influenced bud's growth were soil moisture, soil temperature, soil nutrients, and anthropogenic activity, etc. but they could not be investigated due to resource constraints. Looking across all the models, the number of host plant's visible roots (ROOT) was a strong ( $\alpha=0.05$ or better) ecological factor influencing $R$. kerrii's bud growth. This variable is a proxy that measures the host plant's ecological ability (plant size, vigour, and capacity to provide base) for the proliferation of Rafflesia This seems to be in support of the view that Rafflesia highly correlates with their host plants' conditions (Akhriadi et al., 2010). In a recent study, it was found that the number of Rafflesia's buds increased with the class-size of the host plant (Kedri et al., 2018). The lin-log model also indicates that temperature (TEM) and plant's survival $x$ growth condition (CONST) were strongly ( $\alpha=0.05$ or better) influencing bud growth while light shading (SHADE) and soil acidity $(\mathrm{pH})$ could have been important growth factors as well $(\alpha=0.10)$.

Based on the lin-log HEC model, two related quantities of effects of ecological factors on $R$. kerrii's bud growth can be computed. First, the marginal effect of factor, i.e. $\delta \mathrm{Y} / \delta \mathrm{X}=$ $\beta \times 1 / \mathrm{X}$; and second, the growth sensitivity to ecological factor, i.e. $\zeta=(\delta \mathrm{Y} / \delta \mathrm{X}) \times(\mathrm{X} / \mathrm{Y})=$ $/ Y$, where $\beta=$ regression coefficient; $X=$ value of ecological factor; and $Y=$ value of bud growth). Using the sample's average values (Table $1 \& 4$ for base figures), these effects were calculated and shown in Table 5.

From Table 5, a less acidic soil (higher $\mathrm{pH}$ value) could have contributed the most to $R$. kerrii's marginal bud growth, followed by a better ecological ability of the host plant, and a higher temperature. Light shading exerted quite a small amount to bud's marginal growth while the interaction between the plant's survival condition and growth stage has tended to distract bud growth. However, this could have depended indirectly on some other ecological aspects. For example, apart from its ability to reach advanced growth stages, such as stages II and III, chances of plant's survival condition could have also been influenced by plant abundance on a particular site. In turn, the ability to reach such growth stages could have been determined by many other factors, such as the absence of human and/or animal disturbance throughout the growth period.

Bud growth was highly sensitive to temperature $(\zeta=5.9)$ that a $1 \%$ increase in temperature could have encouraged $2.66 \mathrm{~cm}$ and $8.40 \mathrm{~cm}$ in bud's growth. The latter was also sensitive to light shading $(\zeta=1.97)$ that a $1 \%$ increase in light shading could have increased $0.28 \mathrm{~cm}$ and $0.9 \mathrm{~cm}$ in bud's growth. This was followed by host plant's ecological ability $(\zeta=1.57)$ to support $R$. kerrii whereby a $1 \%$ increase in it could have induced 2.74 $\mathrm{cm}$ and $8.6 \mathrm{~cm}$ of bud's growth. Bud' growth was less sensitive to soil acidity $(\zeta=1.24)$, but a $1 \%$ increase in it could have induced $2.94 \mathrm{~cm}$ and $9.27 \mathrm{~cm}$ in bud's growth. 
Table 5

Estimated effects of pertinent ecological factors on bud growth

\begin{tabular}{|c|c|c|c|c|c|c|}
\hline \multirow[t]{2}{*}{ Ecological factors } & \multicolumn{3}{|c|}{ Bud diameter $(\mathrm{cm})$} & \multicolumn{3}{|c|}{ Bud circumference $(\mathrm{cm})$} \\
\hline & \multicolumn{6}{|c|}{ Marginal effect of ecological factor } \\
\hline Host plant's ecological ability (ROOT) & $17.977 \times 1 / 6.56$ & $=$ & 2.74 & $56.4202 \times 1 / 6.56$ & $=$ & 8.60 \\
\hline Temperature (TEM) & $67.706 \times 1 / 25.44$ & $=$ & 2.66 & $213.7030 \times 1 / 25.44$ & $=$ & 8.40 \\
\hline Light shading (SHADE) & $22.552 \times 1 / 79.32$ & $=$ & 0.28 & $71.1368 \times 1 / 79.32$ & $=$ & 0.90 \\
\hline Soil acidity $(\mathrm{pH})$ & $14.257 \times 1 / 4.84$ & $=$ & 2.94 & $44.8569 \times 1 / 4.84$ & $=$ & 9.27 \\
\hline $\begin{array}{l}\text { Plant's survival condition x growth } \\
\text { stage (CONST) }\end{array}$ & $-2.235 \times 1 / 0.32$ & $=$ & -6.98 & $-7.0254 \times 1 / 0.32$ & $=$ & -21.95 \\
\hline Elevation & & & n.s. & & & n.s. \\
\hline Humidity & & & n.s. & & & n.s. \\
\hline \multirow[t]{2}{*}{ Termite infestation } & & & n.s. & & & n.s. \\
\hline & \multicolumn{6}{|c|}{ Growth sensitivity* to ecological factor } \\
\hline Host plant's ecological ability (ROOT) & $17.977 / 11.46$ & $=$ & 1.57 & $56.4202 / 36.00$ & $=$ & 1.57 \\
\hline Temperature (TEM) & $67.706 / 11.46$ & $=$ & 5.91 & $213.7030 / 36.00$ & $=$ & 5.94 \\
\hline Light shading (SHADE) & $22.552 / 11.46$ & $=$ & 1.97 & $71.1368 / 36.00$ & $=$ & 1.98 \\
\hline Soil acidity $(\mathrm{pH})$ & $14.257 / 11.46$ & $=$ & 1.24 & $44.8569 / 36.00$ & $=$ & 1.25 \\
\hline $\begin{array}{l}\text { Plant's survival condition x growth } \\
\text { stage (CONST) }\end{array}$ & $-2.235 / 11.46$ & $=$ & -0.20 & $-7.0254 / 36.00$ & $=$ & -0.20 \\
\hline Elevation & & & n.s. & & & n.s. \\
\hline Humidity & & & n.s. & & & n.s. \\
\hline Termite infestation & & & n.s. & & & n.s. \\
\hline
\end{tabular}

* Value > 1.0 was 'sensitive'; the larger the value the more sensitive was bud growth to a particular ecological factor. n.s. $=$ not statistically significant

Rather sensitive to host plant's ecological ability $(\zeta=1.57)$, bud's growth can potentially increase by $2.74 \mathrm{~cm}$ and $8.60 \mathrm{~cm}$ respectively by a $1 \%$ increase in the number of host plant's roots/vines. Although not easy to explain, expanded host plant's ecological ability could have provided a better niche for this parasitic plant to grow. By contrast, bud's growth was insensitive to the interaction of Rafflesia kerrii's survival condition and its growth stage. Still, the negative marginal effect of this ecological factor on bud's growth could have been substantial. The struggle of the plant to grow throughout its life stages tended to have suppressed the plant so much so causing the diameter and circumference of the bud to have reduced by $6.98 \mathrm{~cm}$ and $21.95 \mathrm{~cm}$, respectively.

\section{CONCLUSION}

Based on the cross-sectional study, it was shown that the regression model can be applied to objectively estimate the effects of ecological factors on Rafflesia kerrii's bud's growth. Host plant's ecological ability, level of temperature, light shading, soil acidity, and interaction between plant survival condition and growth stage were found to be significant 
and influential ecological factors to R. kerrii's bud growth. Future studies can further corroborate this finding by explicitly investigating the ideal levels of these factors that will maximize $R$. kerrii's bud growth. Termite infestation was said to be the leading cause of failure in Rafflesia's bud growth (Kedri et al., 2018). However, the small sample size has inhibited a positive result of this factor and, thus, future studies may focus on the role/ effect of not only termites but also other organisms on Rafflesia's bud growth. Further, with a small sample, there was insufficient evidence of statistically significant random variation in the influence of altitude and air humidity on $R$. kerrii's bud growth. Further studies may re-assess the ecological impact of these factors using a larger sample covering a larger geographic area - possibly across different localities.

\section{LIMITATION OF THE STUDY}

A few factors deserve consideration for future study. First, the ecological factors other than those included in this study should be further investigated as to their role in influencing Rafflesia's bud growth. There might be other pertinent in-situ micro factors determining bud growth of $R$. kerrii, but their cross-sectional measurements were difficult. Second, the length of time of experiment on soil moisture and light intensity, for example, need to be gauged over a long period of time (say a few hundred days) to cover periodic water-abundant and water-scarce periods (rainy and dry months) as well as possible diurnal variations. Light intensity/shading needs a specific experiment on how Rafflesia could have responded to it over a period of time. Perhaps, daily, weekly, or monthly micro temperature variations need also be recorded throughout the study period. The same goes for day-length photoperiod, which was difficult to measure due to resource constraints.

Third, the anthropogenic threats to bio-diversity which is understandable, but they are difficult to assess because the degree of trampling and disturbance by human or animals (e.g. intensity, frequency or severity, length of time, etc.) on individual Rafflesia plants were not easy to quantify. The negative marginal effect of this ecological factor on Rafflesia's bud growth was quite substantial; it reduced bud's diameter and circumference by 6.98 $\mathrm{cm}$ and $21.95 \mathrm{~cm}$, respectively, but this was considered an indirect factor. The possible direct factors will require some detailed anthropogenic studies to be carried out. Fifth, the forest soils are known to be deficient in many micro- and macro-nutrients, however, in-situ quantification of soil nutrients was quite troublesome due to resource constraints since it could have involved measurements and analysis of many nutrient elements. Sixth, the factors affecting the host plant, Tetrastigma, must be spatially correlated with the survival of Rafflesia's over a large geographic area. The ratio of male and female flowers that may influence the rate of pollination needs to be modelled over a sufficiently large geographic region to provide a sufficient random variation to explain its influence on the plant species' multiplication. All these should provide an avenue for more statistical-based analyses in future. 


\section{ACKNOWLEDGEMENT}

The authors would like to thank Universiti Malaysia Kelantan for the physical resources provided throughout this research. Special thanks to Majlis Daerah Gua Musang and Pejabat Tanah dan Jajahan Kecil Lojing for their helps and assistance to conduct this research at Tanah Tinggi Lojing, Gua Musang.

\section{REFERENCES}

Akhriadi, P., Kiswanto, H. A., Taufiq, A., Alfajri, D., \& Kardiman, R. (2010). Assessment of conservation status of Rafflesia in West Sumatra, Indonesia. Final Report to Rufford Small Grant (For Nature Conservation). Rafflesia Monitoring Team (RMT) Padang, Indonesia.

Anon. (2003). Biological Diversity 2003 - The genus Rafflesia. Biology 226 class project on the conservation of global biodiversity, Earlham College. Retrieved December 17, 2019, from http://legacy.earlham. edu/ givenbe/Rafflesia/rafflesia/biodiv2.htm.

Balete, D. S., Pelser, P. B., Nickrent, D. L., \& Barcelona, J. F. (2010). Rafflesia verrucosa (Rafflesiaceae), a new species of small-flowered Rafflesia from eastern Mindanao, Philippines. Phytotaxa, 10(1), 49-57.

Bareja, B. G. (2011). Biotic factors and their interaction with plant. Retrieved December 17, 2019, from https:// www.cropsreview.com/biotic-factors/html.

Barkman, T. J., Lim, S. H., Salleh, K. M., \& Nais, J. (2004). Mitochondrial DNA sequences reveal the photosynthetic relatives of Rafflesia, the world's largest flower. Proceedings of the National Academy of Sciences, 101(3), 787-792. https://doi.org/10.1073/pnas.0305562101

Beaman, R. S., Decker, P. J., \& Beaman, J. H. (1988). Pollination of Rafflesia (Rafflesiaceae). American Journal of Botany, 75(8), 1148-1162. https://doi.org/10.1002/j.1537-2197.1988.tb08828.x

Belsley, D. A., Kuh, E., \& Welsch, R. E. (1980). Regression Diagnostics: Identifying influential data and sources of collinearity. John Wiley. http://dx.doi.org/10.1002/0471725153.

Chu, Z. F., Wen, J., Yang, Y. P., Nie, Z. L., \& Meng, Y. (2018). Genome size variation and evolution in the grape family Vitaceae. Journal of Systematics and Evolution, 56(4), 273-82. https://doi.org/10.1111/jse.12310

Cotrell, A. \& Luccetthi, R. J. (2005). Gretls user's guide. Gnu Regression, Econometrics and Time Series.

Faust, J. E., \& Lewis, K. P. (2005). (66) Modeling Flower Bud Development of Impatiens hawkeri and I. walleriana. HortScience, 40(4), 1013A-1013. https://doi.org/10.21273/HORTSCI.40.4.1013A

Faye, F. (2008). Habitat comparison of Rafflesia keithii in village area [Unpublished B.Sc. thesis]. Universiti Malaysia Sabah.

Galindon, J. M. M., Ong, P. S. \& Fernando, E. S. (2016). Rafflesia consueloae (Rafflesiaceae), the smallest among giants; a new species from Luzon Island, Philippines. PhytoKeys, (61), 37-46. https:/doi. org/10.3897/phytokeys.61.7295.

Greene, W. H. (1990). Econometric analysis. Mcmillan Publishing Company. 
Grenz, J., Manschadi, A. H., Uygur, N., \& Sauerborn, J. (2005). Effects of environment and sowing date on the competition between faba bean (Vicia faba) and the parasitic weed Orobanche crenata. Field Crop Research, 93(2-3), 300-313. https://doi.org/10.1016/j.fcr.2004.11.001

Griffiths, E. G., Hill, R. C., \& Judge, G. G. (1993). Learning and practicing econometrics. John Wiley \& Sons, Inc.

Hakkinen, R. (1999). Statistical evaluation of bud growth theories: Application to bud burst of betula pendula leaves. Tree Physiology, 19(9), 613-618. https://doi.org/10.1093/treephys/19.9.613

Häkkinen, R., Linkosalo, T., \& Hari, P. (1998). Effects of dormancy and environmental factors on timing of bud burst in Betula pendula. Tree Physiology, 18(10), 707-712. https://doi.org/10.1093/treephys/18.10.707

Hautier, Y., Hector, A., Vojtech, E., Purves, D., \& Turnbull, L. A. (2010). Modelling the growth of parasitic plants. Journal of Ecology, 98(4), 857-866. https://doi.org/10.1111/j.1365-2745.2010.01657.x

Hidayati, S. N., \& Walck, J. L. (2016). A review of the biology of Rafflesia: What do we know and what's next? Botanic Garden Bulletin, 19(2), 67-78.

Hinkley, D. V. (1977). Jackknifing in unbalanced situations. Technometrics, 19(3), 285-292.

Inger, R. F., \& Lian T. F. (1996). The natural history of amphibians and reptiles in Sabah. Natural History Publication (Borneo).

Jamili, N., \& Wilcock, C. C. (1998). The Rafflesia conservation incentive scheme in Sabah, Malaysian Borneo. Sabah Parks Nature Journal, 1, 9-17.

Jamili, N., Baikan, B., \& Sinun, W. (2000). Nature conservation: striking a balance between conservation and development for Sabah beyond 2000. Sabah Beyond, 181-202.

Jamili, N. (2001a). Rafflesia of the world. Natural History Publications (Borneo).

Jamili, N. (2001b). Life cycle and flower bud growth. In Rafflesia of the world (p. 13). Natural History Publications (Borneo).

Jumaat, H. A., Afiq, A. J. M., Rahmah, M., Wahab, N. A. A., Syamsurina, A., Paiz, K. M., Raih, M. F. M., \& Wan, K. L. (2016). Rafflesia tuanku-halimii (Rafflesiaceae), a new species from Peninsular Malaysia. Sains Malaysiana, 45(11), 1589-1595.

Kanchanapoom, T., Kamel, M. S., Picheansoonthon, C., Luecha, P., Kasai, R., \& Yamasaki, K. (2007). Hydrolyzable tannins and phenylpropanoid from Rafflesia kerrii Meijer (Rafflesiaceae). Journal of Natural Medicines, 61(4), 478-479. https://doi.org/10.1007/s11418-007-0181-4

Kedri, F. K., Hamzah, Z., Sukri, N. S., Yaacob, S. H., Abd Majid, N. K. S., Mokhtar, N., \& Amir, S. F. (2018). Distribution and ecology of Rafflesia in Royal belum state park, Perak, Malaysia. International Journal of Engineering and Technology, 7(2.29), 292-296.

Koya, P. R., \& Goshu, A. T. (2013). Generalized mathematical model for biological growths. Open Journal of Modelling and Simulation, 1, 42-53. https://doi.org/10.4236/ojmsi.2013.14008

Kramer, K. (1994). Selecting a model to predict the onset of growth of Fagus sylvatica. Journal of Applied Ecology, 31(1), 172-181. https://doi.org/10.2307/2404609 
Kumar, S. (2018). Ecological factors that affect the growth of plants. Retrieved on December 17, 2019, from http://www.biologydiscussion.com/growth-of-plants/ecological-factors-that-affect-the-growth-of-plantswith-diagrams/15288.

Latifah, D., Riswati, M. K., Handini, E., \& Wawangningrum, H. (2017). Viability test on the seeds of Rafflesia arnoldii R. Br. \& R. patma Blume. Buletin Kebun Raya, 20(1), 25-32.

Latiff, A. (2018). Viability of having the gigantic Rafflesia flower in our park. Open Access Journal of Science, 2(2), 106-107.

Linksolo, T., Carter, T. R., Hakkinen, R., \& Hari, P. (2000). Predicting spring phenology and frost damage risk of Betual spp. under climatic warming: A comparison of two models. Tree Physiology, 20(17), 1175-1182. https://doi.org/10.1093/treephys/20.17.1175

Long, J. S., \& Ervin, L. H. (1998). Correcting for heteroscedasticity with heteroscedasticity consistent standard errors in the linear regression model: small sample considerations. Indiana University, Bloomington, IN, $47405,1-33$.

MacKinnon, J. G., \& White, H. (1985). Some heteroskedasticity-consistent covariance matrix estimators with improved finite sample properties. Journal of Econometrics, 29(3), 305-325. https://doi.org/10.1016/03044076(85)90158-7

Maddala, G. S. (1977). Econometrics. McGraw-Hill Book Company Publishing.

Maddala, G. S. (1992). Introduction to econometrics (2nd Ed.). Maxwell Macmillan International Publishing.

Mahyuni, R., Kusuma, Y. W. C., Wihermanto, W., \& Veldkamp, J. (2015). Notes on Rafflesia (Rafflesiaceae) In Sumatra with A New Record Rafflesia Gadutensis Meijer. Reinwardtia, 14(2), 317-322. https://doi. org/10.14203/reinwardtia.v14i2.1678

Martin, G. (1998). Etnobotany. Natural History Publications (Borneo).

Medel, R. (2000). Assessment of parasite-mediated selection in a host-parasite system in plants. Ecology, 81(6), 1554-1564. https://doi.org/10.1890/0012-9658(2000)081[1554:AOPMSI]2.0.CO;2

Meijer, W. (1984). New species of Rafflesia (Rafflesiaceae). Blumea, 30(1), 209-215.

Mello, M. A., \& Tuan, R. S. (1999). High density micromass cultures of embryonic limb bud mesenchymal cells: an in vitro model of endochondral skeletal growth. In Vitro Cellular \& Growthal Biology-Animal, 35(5), 262-269. https://doi.org/10.1007/s11626-999-0070-0

Milon, J. W., Gressel, J., \& Mulkey, D. (1984). Hedonic amenity valuation and functional form specification. Land Economics, 60(4), 378-87. https://doi.org/10.2307/3145714

Molina, J., Hazzouri, K. M., Nickrent, D., Geisler, M., Meyer, R. S., Pentony, M. M., Flowers, J. M., Pelser, P., Barcelona, J., Inovejas, S. A., Uy, I., Yuan, W., Wilkins, O., Michel, C. I., LockLear, S., Concepcion, G. P., \& Purugganan, M. D. (2014). Possible loss of the chloroplast genome in the parasitic flowering plant Rafflesia lagascae (Rafflesiaceae). Molecular Biology and Evolution, 31(4),793-803. https://doi. org/10.1093/molbev/msu051

Montgomery, R. A. (2004). Effects of understory foliage on patterns of light attenuation near the forest floor. Biotropica, 36(1), 33-39. https://doi.org/10.1111/j.1744-7429.2004.tb00293.x 
Moreau, D., Gibot-Leclerc, S., Giardin, A., Pointurier, O, Reibel, C., Strbik, F., Fernandez-Aparicio, M., \& Colbach, N. (2016). Trophic relationships between the parasitic plant species Phelipanche ramosa (L.) and different hosts depending on host phenological stage and host growth rate. Frontiers in Plant Science, 7, 1-12. https://doi.org/10.3389/fpls.2016.01033

Mursidawati, S. (2015). Morphology of fruits and seeds of Rafflesia patma and R. arnoldii. Buletin Kebun Raya, 15 (1), 21-30.

Mursidawati, S. (2017). Ex-situ conservation of Rafflesia patma (Rafflesiaceae) in Bogor Botanical Gardens (Indonesia). Nature Conservation Research, 2(2), 90-91.

Mursidawati, S., \& Risawati, M. K. (2009, July 14). Conservation biology of holoparasit plant: in vitro seeds innoculation of Rafflesia patma [Paper presentation]. Proceedings of a Seminary on Flora Coonservation in Addressing the Impact of Global Warming, Tabahan, Bali, Indonesia.

Nasihah M., Zulhazman H., Siti-Munirah M. Y., Razak W., Fatimah, K., \& Qayyum-Nadia, W. A. (2016). Tetrastigma hookeri (Laws.) Planch (Vitaceae), a host plant for Rafflesia kerrii Meijer in Peninsular Malaysia. Malayan Nature Journal, 68(Part 1 \& 2), 33-39.

Nasihah, M., Zulhazman, H., Siti-Munirah, M. Y., Razak, W., Fatimah, K., \& Qayyum-Nadia W. A. (2013). Soil nutrient dynamic at three defined elevations in relation to bud population of Rafflesia kerrii in Lojing Highland of Kelantan, Malaysia. Universiti Malaysia Kelantan Press.

Nery, S., Kamarudin, M. S., Khairil, M., Nor-Zuhailah, M. N., Hasein, M. R. A., \& Burslem, D. F. R. P. (2016). Rafflesia parvimaculata (Rafflesiaceae), a new species of Rafflesia from Peninsular Malaysia. Phytotaxa, 253(3), 207-213. https://doi.org/10.11646/phytotaxa.253.3.4

Nickrent, D. L., Blarer, A., Qiu, Y. L., Vidal-Russell, R., \& Anderson, F. E. (2004). Phylogenetic inference in Rafflesiales: The influence of rate heterogeneity and horizontal gene transfer. BMC Evolutionary Biology, 4(40), 1-17. https://doi.org/10.1186/1471-2148-4-40

Osawa, A., Shoemaker, C. A., \& Stedinger, J. R. (1983). A stochastic model of balsam fir bud phenology utilizing maximum likelihood parameter estimation. Forest Science, 29(3), 478-490. https://doi.org/10.1093/ forestscience/29.3.478

Paine, C. T., Marthews, T. R., Vogt, D. R., Purves, D., Rees, M., Hector, A., \& Turnbull, L. A. (2012). How to fit nonlinear plant growth models and calculate growth rates: an update for ecologists. Methods in Ecology and Evolution, 3(2), 245-256. https://doi.org/10.1111/j.2041-210X.2011.00155.x

Peters, R. F., \& Ting, Y. Y. (2016). Protection of Rafflesia through the appreciation of the Dusun's indigenous knowledge: A preliminary case study at Poring-Sabah. Journal of Tropical Biology and Conservation, $13,27-42$.

Qayyum, W. A., Yunoh, S. M. M., Hamzah, Z., \& Wahab, R. (2012, July 9-11). A preliminary study on the mortality rates of Rafflesia kerriii in the Lojing Highlands, Gua Musang, Kelantan, Malaysia [Paper presentation]. UMT $11^{\text {th }}$ International Annual Symposium on Sustainability Science and Management, Terengganu, Malaysia.

Ramamoorthy, R., Phya, E. E. K., Lim, S. H., Tan, H. T. W., \& Kumar, P. P. (2013). Identification and characterization of RcMADS1, an AGL24 Ortholog from the Holoparasitic Plant Rafflesia cantleyi SolmsLaubach (Rafflesiaceae). PLoS ONE, 8(6), Article e67243. https://doi.org/10.1371/journal.pone.0067243 
Salleh, K. M. (2007). Rafflesia. Borneo Publishing Company.

Saxe, H., Cannell, M. G., Johnsen, Ø., Ryan, M. G., \& Vourlitis, G. (2001). Tree and forest functioning in response to global warming. New Phytologist, 149(3), 369-399. https://doi.org/10.1046/j.14698137.2001.00057.x

Shaw, J. (2017, March-April). Colossal blossom - Pursuing the peculiar genetics of a parasitic plant. Havard Magazine. Retrieved December 19, 2019, from https://harvardmagazine.com/2017/03/colossal-blossom.

Susatya, A. (2011). Rafflesia: The world's largest flower charm. Directorate for conservation areas and protected forest growth. Department of Forestry, Jakarta, Indonesia.

Veldkamp, J. F. (2009). Notes of the names of the Tetrasigma (Vitaceae) host of Rafflesia (Rafflesiaceae). Reinwardtia, 13(1), 75-78. https://doi.org/10.14203/reinwardtia.v13i1.431

Wicaksono, A., \& Da Silva, J. A. T. (2015). Short communication: Attempted callus induction of holoparasite Rafflesia patma Blume using primordial flower bud tissue. Nusantara Biosicence, 7(2), 96-101.

Wikipedia. (2018). Heteroscedasticity-consistent standard errors. Retrieved December 24, 2019, from htpps:// en.m.wikipedia.org/ 